\title{
Intra-community spatial variability of particulate matter size distributions in Southern California/Los Angeles
}

\author{
M. Krudysz ${ }^{1}$, K. Moore ${ }^{2}$, M. Geller ${ }^{2}$, C. Sioutas ${ }^{2}$, and J. Froines ${ }^{1}$ \\ ${ }^{1}$ Center for Occupational and Environmental Health and the Department of Environmental Health Sciences, University of \\ California, Los Angeles, CA 90095, USA \\ ${ }^{2}$ Department of Civil and Environmental Engineering, University of Southern California, 3620 South Vermont Avenue, \\ Los Angeles, CA 90089, USA
}

Received: 10 March 2008 - Published in Atmos. Chem. Phys. Discuss.: 27 May 2008

Revised: 17 November 2008 - Accepted: 1 January 2009 - Published: 12 February 2009

\begin{abstract}
Ultrafine particle (UFP) number concentrations vary significantly on small spatial and temporal scales due to their short atmospheric lifetimes and multiplicity of sources. To determine UFP exposure gradients within a community, simultaneous particle number concentration measurements at a network of sites are necessary. Concurrent particle number size distribution measurements aid in identifying UFP sources, while providing data to investigate local scale effects of both photochemical and physical processes on UFP. From April to December 2007, we monitored particle number size distributions at 13 sites within $350 \mathrm{~m}-11 \mathrm{~km}$ of each other in the vicinity of the Ports of Los Angeles and Long Beach using Scanning Mobility Particle Sizers (SMPS). Typically, three SMPS units were simultaneously deployed and rotated among sites at 1-2 week intervals. Total particle number concentration measurements were conducted continuously at all sites. Seasonal and diurnal number size distribution patterns are complex, highly dependent on local meteorology, nearby PM sources, and times of day, and cannot be generalized over the study area nor inferred from one or two sampling locations. Spatial variation in particle number size distributions was assessed by calculating the coefficient of divergence (COD) and correlation coefficients $(r)$ between site pairs. Results show an overall inverse relationship between particle size and CODs, implying that number concentrations of smaller particles $(<40 \mathrm{~nm})$ differ from site to site, whereas larger particles tend to have similar concentrations at various sampling locations. In addition, variations in $r$ values as a function of particle size are not necessarily consistent with corresponding COD values, indicating that using results from correlation analysis alone may not accurately assess spatial variability.
\end{abstract}

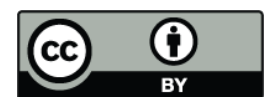

Correspondence to: M. Krudysz (megk@ucla.edu)

\section{Introduction}

Vehicular traffic constitutes one of the most significant urban sources of ultrafine particle number concentrations (Geller et al., 2005; Ketzel et al., 2004). People living and working in close proximity to heavily trafficked roadways are likely to be exposed to concentrations well above normal ambient levels. Ultrafine particles (UFPs) make up the majority of ambient particle number concentrations but only a small fraction of ambient PM mass. Given that there is generally little or no correlation between overall UFP number and $\mathrm{PM}_{2.5}$ mass (Singh et al., 2006; Keywood et al., 1999), measurements of ambient particle number concentrations have become increasingly important (Rosenbohm et al., 2005). Measurements of ambient UFP number concentrations at a single central monitoring station may not be indicative of actual human exposure in a community (Monn, 2001). In order to address this issue, more intensive particle number measurements on finer spatial scales are needed. Although few studies to date have focused on the spatial variability of UFP number concentrations and size distributions, most conclude that, in contrast to particle mass, particle number concentrations can vary widely over a study area. Studies in various locations throughout the world have shown substantial spatial variability in particle number concentrations (Puustinen et al., 2007; Turner, 2008). Vehicular emissions and the location in the center of the city have been shown to be significant predictors of spatial variation, with larger effects for particle numbers than for fine particle mass (Lianou et al., 2007). A recent investigation in urban Basle showed that daytime profiles for UFP number concentrations were more closely related to the number of heavy-duty vehicles than to the number of light-duty vehicles, implying that diesel exhaust is a strong source of ultrafine PM (Junker et al., 2000).

UFP monitoring is challenging due to the combination of high spatial and temporal variability in particle concentration

Published by Copernicus Publications on behalf of the European Geosciences Union. 


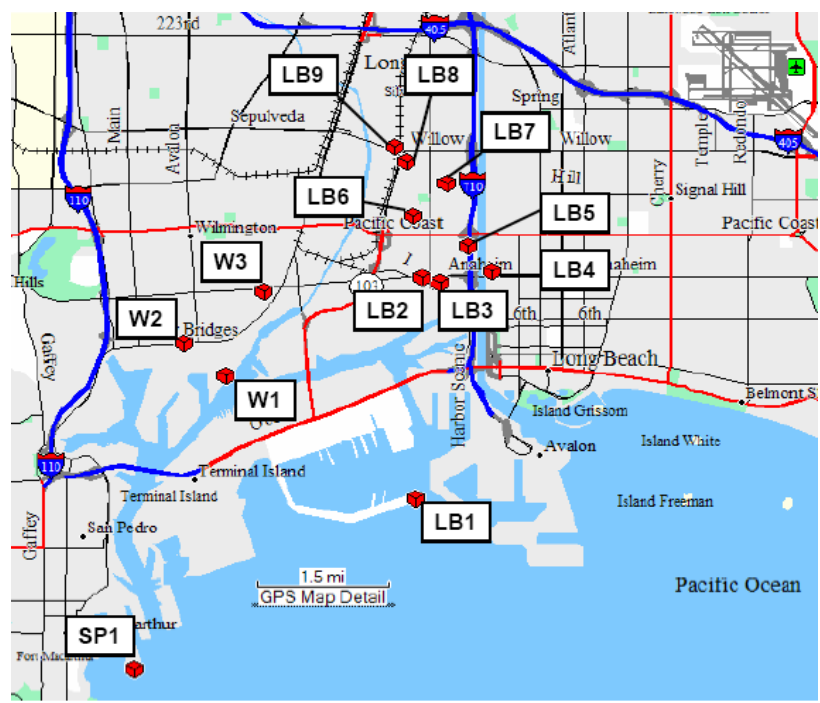

Fig. 1. SMPS sampling sites (latitude and longitude coordinates provided in Moore et al., 2009).

coupled with the expense to monitor at multiple locations. In addition, measurements of only UFP total number concentration do not provide information on particle number size distribution, which can be important from a health standpoint because of differences in respiratory deposition of differently sized particles (Kim and Jaques, 2000). Ambient aerosols undergo atmospheric transformation after emission from a source due to processes such as condensation of low volatility products of photochemical reactions, evaporation of higher volatility particle-bound species, dilution with clean air, entrainment of polluted air, and coagulation, thereby modifying the shape of the particle number size distribution (Jeong et al., 2004; Zhang and Wexler, 2002; Kerminen et al., 2007). Number size distribution measurements can help in identifying the types of aerosols present at different sampling sites and the effects of photochemistry and aerosol aging on a local scale.

Resolution of sources using particle number size distribution measurements in urban and suburban atmospheres can be difficult due to the collective influence of a wide range of sources and meteorological factors. A number of studies have shown that vehicular emissions and atmospheric transformation processes result in particle number size distributions with 2 or 3 dominant particle side modes. These modes arise from the evolution of the particles from tail pipes of vehicles to the urban atmosphere. Rapid dilution of the vehicle exhaust and the formation of nucleation mode particles smaller than $30 \mathrm{~nm}$ occurs within a few meters behind a moving vehicles, while particle growth through coagulation and other processes occurs within tens of meters from a vehicle (Zhang et al., 2004). Uni-modal particle number size distributions have also been found in urban environments, especially in close proximity to vehicular exhaust emissions.
Only measurements taken with a thermodenuder showed that the size distribution consisted of the accumulation mode and the more volatile nucleation mode (Ronkko et al., 2007). In addition, for small distances behind a vehicle being investigated, no nucleation modes were observed, only a unimodal particle number size distribution (Morawska et al., 2007). Researchers have also noted that the size of the nucleation mode particles is really small and that at most driving conditions, the geometric mean diameter of nucleation mode is less than $10 \mathrm{~nm}$. Limiting the lower measured size to $>10 \mathrm{~nm}$ can result in missing the nucleation mode, therefore the measurement range of the instruments is an important issue in nucleation mode studies (Ronkko et al., 2006).

Analysis of particle number size distributions can help to identify emissions from diesel versus gasoline vehicles, background urban emissions, secondary and transported aerosols, fresh versus aged particles, or differences between primary particles emitted from new and older engines ( $\mathrm{Su}$ et al., 2004; Ogulei et al., 2007). In laboratory tests, gasoline and diesel engine exhaust showed particle number size distributions with mean diameters ranging from $40-80 \mathrm{~nm}$ and 60-120 nm, respectively (Harris and Maricq, 2001). In urban atmospheric conditions, heavy duty engines emit particles with mean diameters between 60 and $80 \mathrm{~nm}$ (Lehmann et al., 2003) and spark-ignition engine emissions show bimodal number size distributions with average values of the count median diameter ranging from 40 to $60 \mathrm{~nm}$ (Ristovski et al., 1998).

The objectives of this study were to measure particle number size distributions at multiple sites within a community impacted by numerous local sources and to identify the temporal profiles of particle number size distributions at each site. We investigated the spatial variability of PM as a function of particle size and quantitatively assessed these results using coefficients of divergence and correlation coefficients. Number size distribution measurements were conducted at 13 sites in the vicinity of the Ports of Los Angeles (PoLA) and Long Beach (PoLB) using Scanning Mobility Particle Sizers, with simultaneous measurements at three to four distinct sites. The health and environmental consequences of air pollution impacts resulting from goods movement are substantial, therefore accurate assessment of the spatial variability of UFP number concentrations and number size distributions can help in identifying exposure hotspots. A companion study of total UFP number concentrations is reported in Moore et al. (2009) and those results will not be discussed in detail here. These studies were conducted in conjunction with the multi-investigator Harbor Communities Monitoring Study sponsored by the California Air Resources Board. 


\section{Experimental methods}

\subsection{Sampling sites}

The sampling sites are located in the San Pedro/Wilmington/Long Beach, CA area, which includes a complex mix of industrial (refineries, power plants), and transportation sources (marine vessels, diesel trucks, port activities) influencing UFP number concentrations and size distributions. The community was monitored for a 9-month sampling period to capture the changes in particle size distribution associated with seasonal variations as well as the peak in port activities that occurs in October. Thirteen sampling sites are shown in Fig. 1. SP1 is located in the city of San Pedro, sites W1-W3 are located in Wilmington, and sites LB1-LB9 are part of the city of Long Beach. The sites are $320 \mathrm{~m}$ to $11 \mathrm{~km}$ apart and are located in and around the PoLA and PoLB. The ports are the entry point for almost half $(40 \%)$ of all cargo entering the United States annually, and substantial growth in port container traffic is expected in the next ten years (Mercer Management Consulting, 2001). The combined Ports and related port activities such as ships, cargo handling equipment, locomotives, and heavy-duty diesel trucks are collectively a dominant source of criteria pollutants such as $\mathrm{SO}_{2}$ and $\mathrm{NO}_{\mathrm{x}}$ in Southern California and are subject to increasing scrutiny.

During each 1 to 3-week sampling period, particle number concentrations and size distributions were measured simultaneously at two to four sampling sites. Table 1 shows the sampling period at each site, along with the number of valid observation in each sampling period, meteorological parameters, and particle number statistics. Except for the nearly continuous W2 data, monthly information from all the other sites includes only data from the actual sampling days. For example, July and December data include only 18 and 11 days, respectively. The sites sampled concurrently were chosen based on the proximity to each other to identify differences between sites on a macro-scale and the dissimilarity in potential sources influencing UFP concentrations. Each site was visited twice a week to download data and to ensure proper operation of all instruments.

SP1 is the background site located at the edge of the Pacific Ocean; it is mostly upwind of Port activities and is not close to significant motor vehicle traffic. It was sampled in the summer and the winter period to determine to what extent seasons influence particle number concentrations at a location impacted minimally by local combustion sources. Another background site, LB1, was chosen for comparison to the SP1 site and to determine how emissions from port activities influence particle number size distributions. Site W1 is across a shipping channel and is located north of the PoLA in an industrial area, away from heavily-traveled roadways. Site W2 is located at the intersection of Harry Bridges Boulevard and Fries Avenue, a major arterial roadway with significant diesel truck traffic and is also affected by both port activi- ties and local traffic emissions. The site is directly north of the PoLA and south of the Wilmington city center. The W2 site was monitored continuously during the entire sampling period, thus allowing for both seasonal and spatial comparisons.

The LB2 and LB3 sites were sampled simultaneously in the spring. They are only $320 \mathrm{~m}$ apart from each other and are both influenced by heavy-duty diesel traffic. The I-710 splits the LB4 and the LB5 sites. LB5 is situated just west of the freeway whereas the LB4 site is $275 \mathrm{~m}$ east of that roadway. These sites were sampled concurrently during the summer for comparison of the differences in number size distributions between sites close to a major freeway with an approximately $25-30 \%$ heavy-duty diesel traffic, mainly from the Los Angeles port system (Zhu et al., 2002a). Another pair of concurrently sampled sites (LB8 and LB9) were chosen for their proximity to rail, the heavily diesel-impacted Terminal Island Freeway (SR-103), and the Intermodal Container Transfer Facility (ICTF) a transshipment/transfer point from truck to rail for cargo containers leaving the Ports. LB8 is located adjacent to a school immediately to the east of SR103 , and site LB9 is located approximately $20 \mathrm{~m}$ to the north of its termination at Willow Street. Sites W3, LB6, and LB7 are located in mostly residential portions of the study area and, number concentrations at these locations are influenced mostly by local vehicular emissions.

\subsection{Instrumentation}

A Condensation Particle Counter (CPC, TSI Model 3022A) was used to measure total particle number (PN) concentrations (results reported in Moore et al., 2009) and a Scanning Mobility Particle Sizer (SMPS, TSI Model 3936) was used to measure number based size distributions. The $\mathrm{CPC}$ has a $50 \%$ detection efficiency diameter of $7 \mathrm{~nm}$ increasing to ca. $100 \%$ for particles $>20 \mathrm{~nm}$. The maximum detectable particle size reported by TSI is $>3 \mu \mathrm{m}$. The SMPS system includes a long Differential Mobility Analyzer (TSI, Model 3081) and a butanol-based CPC. The system was set to measure particles in the size range from $14-736 \mathrm{~nm}$ with a total scanning time of $5 \mathrm{~min}$, resulting in 111 size intervals. Aerosol Instrument Manager software (v8.0, TSI) was used to control the SMPS system, log data and export SMPS data. A Vantage Pro 2 Weather Station (Davis Instruments, Hayward, California), installed within 10 feet of the SMPS unit, collected meteorological data including temperature, humidity, and wind speed and direction at each site.

\subsection{Data processing/validation}

The four SMPS units and CPC instruments used throughout the study were tested side-by-side for intra-instrument variability. All four instruments were set to sample the same aerosol simultaneously for approximately $48 \mathrm{~h}$. As with the filed measurements, the instruments were set to measure 
Table 1. Site information for each sampling period. Sampling start and end dates, mean and standard deviations calculated from total particle concentrations, meteorological data, number of hourly means used in analyses, and the average geometric number mean and standard deviation particle size.

\begin{tabular}{|c|c|c|c|c|c|c|c|c|c|c|}
\hline \multirow[b]{2}{*}{ Site } & \multicolumn{2}{|c|}{ Sampling Period } & \multicolumn{2}{|c|}{ Total Conc. (\#/cc) } & \multicolumn{3}{|c|}{ Meteorology } & \multicolumn{3}{|c|}{ SMPS } \\
\hline & Start & End & Mean & SD & $\begin{array}{c}\text { Mean } \\
\text { Temp } \\
\left({ }^{\circ} \mathrm{C}\right)\end{array}$ & $\begin{array}{c}\text { Mean } \\
\text { RH } \\
(\%)\end{array}$ & $\begin{array}{c}\text { Dominant } \\
\text { Wind }\end{array}$ & $n$ & $\begin{array}{c}\text { Geo } \\
\text { Mean } \\
(\mathrm{nm})\end{array}$ & $\begin{array}{c}\text { Geo } \\
\text { SD } \\
(\mathrm{nm})\end{array}$ \\
\hline \multirow[t]{2}{*}{ SP1 } & $12 / 6 / 2007$ & $19 / 7 / 2007$ & $6.3 E+03$ & $4.2 \mathrm{E}+03$ & 18 & 89.6 & $\mathrm{~W}$ & 269 & 73 & 2.1 \\
\hline & $28 / 11 / 2007$ & $7 / 12 / 2007$ & $1.3 \mathrm{E}+04$ & $1.1 \mathrm{E}+04$ & 14 & 73.3 & $\mathrm{~W}$ & 228 & 61 & 1.9 \\
\hline W1 & $17 / 9 / 2007$ & $2 / 11 / 2007$ & $8.2 \mathrm{E}+03$ & $4.7 \mathrm{E}+03$ & 19 & 67.4 & $\mathrm{~N}$ & 1025 & 60 & 2.0 \\
\hline \multirow{7}{*}{ W2 } & $30 / 4 / 2007$ & $8 / 5 / 2007$ & $1.4 \mathrm{E}+04$ & $8.0 \mathrm{E}+03$ & 19 & 52.9 & NW & 183 & 37 & 2.0 \\
\hline & $18 / 7 / 2007$ & $27 / 7 / 2007$ & $1.3 \mathrm{E}+04$ & $7.9 \mathrm{E}+03$ & 22 & 71.8 & $\mathrm{~N}$ & 211 & 44 & 2.1 \\
\hline & $2 / 8 / 2007$ & $31 / 8 / 2007$ & $1.8 \mathrm{E}+04$ & $2.1 \mathrm{E}+04$ & 23 & 66.5 & $\mathrm{~N}$ & 332 & 45 & 2.2 \\
\hline & $1 / 9 / 2007$ & $30 / 9 / 2007$ & $1.3 \mathrm{E}+04$ & $8.3 \mathrm{E}+03$ & 21 & 65.2 & $\mathrm{~N}$ & 514 & 46 & 2.1 \\
\hline & $1 / 10 / 2008$ & $31 / 10 / 2007$ & $1.6 \mathrm{E}+04$ & $9.8 \mathrm{E}+03$ & 19 & 60.8 & $\mathrm{~N}$ & 744 & 43 & 2.1 \\
\hline & $1 / 11 / 2007$ & $30 / 11 / 2007$ & $1.6 \mathrm{E}+04$ & $1.3 \mathrm{E}+04$ & 16 & 71.0 & $\mathrm{~N}$ & 570 & 45 & 2.2 \\
\hline & $1 / 12 / 2007$ & $12 / 12 / 2007$ & $2.1 \mathrm{E}+04$ & $1.2 \mathrm{E}+04$ & 13 & 64.4 & NW & 281 & 37 & 2.0 \\
\hline \multirow[t]{2}{*}{ W3 } & $15 / 5 / 2007$ & $2 / 6 / 2007$ & $9.3 \mathrm{E}+03$ & $5.4 \mathrm{E}+03$ & 18 & 69.1 & SW & 334 & 47 & 2.1 \\
\hline & $13 / 10 / 2007$ & $2 / 11 / 2007$ & $2.5 \mathrm{E}+04$ & $2.1 \mathrm{E}+04$ & 20 & 60.5 & NW & 456 & 34 & 2.0 \\
\hline LB1 & $27 / 11 / 2007$ & $6 / 12 / 2007$ & $1.9 \mathrm{E}+04$ & $1.2 \mathrm{E}+04$ & 15 & 71.7 & NW & 215 & 43 & 1.9 \\
\hline \multirow[t]{2}{*}{ LB2 } & $6 / 4 / 2007$ & $4 / 5 / 2007$ & $1.1 \mathrm{E}+04$ & $6.2 \mathrm{E}+03$ & 16 & 66.5 & SW & 244 & 42 & 1.9 \\
\hline & $3 / 11 / 2007$ & $12 / 11 / 2007$ & $2.6 \mathrm{E}+04$ & $1.4 \mathrm{E}+04$ & 16 & 83.2 & NW & 176 & 46 & 2.0 \\
\hline LB3 & $6 / 4 / 2007$ & $7 / 5 / 2007$ & $1.8 \mathrm{E}+04$ & $1.1 \mathrm{E}+04$ & 16 & 72.0 & $\mathrm{~S}$ & 426 & 42 & 1.9 \\
\hline LB4 & $2 / 8 / 2007$ & $17 / 9 / 2007$ & $1.3 \mathrm{E}+04$ & $7.1 \mathrm{E}+03$ & 23 & 64.7 & $\mathrm{~N}$ & 681 & 41 & 1.9 \\
\hline LB5 & $28 / 8 / 2007$ & $17 / 9 / 2007$ & $3.0 \mathrm{E}+04$ & $1.8 \mathrm{E}+04$ & 23 & 65.6 & $\mathrm{~N}$ & 478 & 44 & 2.0 \\
\hline LB6 & $2 / 11 / 2007$ & $12 / 11 / 2007$ & $1.6 \mathrm{E}+04$ & $7.5 \mathrm{E}+03$ & 16 & 83.0 & $\mathrm{~W}$ & 241 & 35 & 1.9 \\
\hline LB7 & $23 / 7 / 2007$ & $26 / 8 / 2007$ & $1.9 \mathrm{E}+04$ & $1.1 \mathrm{E}+04$ & 23 & 71.7 & SW & 588 & 44 & 2.0 \\
\hline \multirow[t]{3}{*}{ LB8 } & $15 / 5 / 2007$ & $10 / 6 / 2007$ & $8.1 \mathrm{E}+03$ & $5.3 \mathrm{E}+03$ & 17 & 74.0 & SW & 636 & 43 & 2.0 \\
\hline & $13 / 8 / 2007$ & $28 / 8 / 2007$ & $1.2 \mathrm{E}+04$ & $5.9 \mathrm{E}+03$ & 23 & 68.5 & $\mathrm{~W}$ & 332 & 42 & 2.0 \\
\hline & $12 / 11 / 2007$ & $27 / 11 / 2007$ & $2.7 \mathrm{E}+04$ & $1.7 \mathrm{E}+04$ & 16 & 68.8 & W & 288 & 58 & 2.0 \\
\hline \multirow[t]{2}{*}{ LB9 } & $29 / 6 / 2007$ & $24 / 7 / 2007$ & $1.3 \mathrm{E}+04$ & $6.6 \mathrm{E}+03$ & 22 & 73.9 & SW & 252 & 46 & 2.0 \\
\hline & $12 / 11 / 2007$ & $22 / 11 / 2007$ & $2.0 \mathrm{E}+04$ & $1.1 \mathrm{E}+04$ & 17 & 74.1 & $\mathrm{NE}$ & 247 & 44 & 2.0 \\
\hline
\end{tabular}

particles in the size range from $14-736 \mathrm{~nm}$ with a total scanning time of $5 \mathrm{~min}$. One of the well-characterized SMPS was used as a reference instrument to determine the channel-bychannel response of the other instruments. Based on this characterization, a size-specific correction factor for each SMPS was calculated. The size distribution data obtained after application of the correction factors were compared for the four instruments. Results indicated that the instruments did not differ from each other by more than $10 \%$. The correction factors obtained from the side-by-side comparisons were applied to the data collected in the field before data analysis. Corrections to the number size distributions for SMPS inlet losses due to diffusion were calculated as a function of particle diameter using Gormley-Kennedy equations.
Results from each 5-min scan were examined to exclude outliers and the data were converted to hourly averages. Validation of the data obtained by the SMPS system was performed by comparing total particle number concentrations calculated by summing across all size intervals to results obtained from the total count CPC. Although the SMPS system showed on average 20-30\% lower total particle number concentrations, the hourly averages obtained from the two units were highly correlated $(r>0.9)$. Whereas the CPC measures number concentrations for particles ranging from $7 \mathrm{~nm}$ to $>3 \mu \mathrm{m}$, the SMPS configuration used in this study counted particles in the size range from $14-736 \mathrm{~nm}$. Therefore, the SMPS only measured a portion of the particle size range that the CPC detected. Also, the reason why some of 
Table 2. Diurnal patterns in wind direction for selected sites and sampling periods.

\begin{tabular}{l|cc|ccccccc|c|c|c|c|c|c}
\hline & \multicolumn{3}{|c|}{ SP1 } & \multicolumn{1}{c}{ W2 } & LB1 & $\begin{array}{c}\text { LB3 } \\
\text { Apr-May }\end{array}$ & $\begin{array}{c}\text { LB4 } \\
\text { Aug-Sep }\end{array}$ & $\begin{array}{c}\text { LB5 } \\
\text { Aug-Sep }\end{array}$ & $\begin{array}{c}\text { LB9 } \\
\text { Oct-Nov }\end{array}$ \\
\hline 8 p.m.-6 a.m. & W & N & NW & SE & S & SE & N & N & NW & NW & S & SE & SE & N \\
7-10 a.m. & SW & N & S & S & S & S & N & N & N & NW & S & SW & SW & E \\
11 a.m.-2 p.m. & W & W & W & S & N & NW & NW & NW & W & S & SW & SW & W & SW \\
3-7 p.m. & NW & NW & NW & N & NW & NW & NW & NW & NW & W & W & NW & N & SW \\
\hline
\end{tabular}

the particles detected by the CPC were not accounted for by the SMPS may result from the wrong correction of the charging and size dependent detection efficiencies inside the Electrostatic Classifier by the AIM software. Additional observations using an APS conducted simultaneously at many of the sampling sites indicated that very few particles larger than $700 \mathrm{~nm}$ are expected, therefore, it is likely that the real difference between the CPC and the SMPS total particle counts was in the $7-14 \mathrm{~nm}$ range.

\subsection{Statistical analysis}

Accurate assessment of intraurban spatial variability requires analysis using correlation coefficients in conjunction with coefficients of divergence and absolute concentration differences between sites (Wilson et al., 2005). Spearman correlations were used to determine the relationships among the sampling sites. Spatial variability was further assessed by calculating the coefficients of divergence (COD). The COD provides information on the degree of uniformity between sampling sites and is defined as

$\operatorname{COD}_{f h}=\sqrt{\frac{1}{n} \sum_{i=1}^{n}\left(\frac{x_{i f}-x_{i h}}{x_{i f}+x_{i h}}\right)^{2}}$

Where $x_{i f}$ is the $i$ th hourly averaged concentration at a given size interval measured at site $f, f$ and $h$ are two different sites, and $n$ is the number of observations. Small COD values imply similarities between the concentrations measured at various sites, while COD values approaching unity indicate vast differences between sites. The accuracy of the number concentration measurements is limited by statistical error at the higher end of the number size distribution. Therefore, the last 19 size intervals (covering the range of $385-736 \mathrm{~nm}$ ) were combined into 3 size bins $(385-414 \mathrm{~nm}, 429-495 \mathrm{~nm}$, $514-736 \mathrm{~nm}$ ) for the COD analysis. This binning resulted in less than $10 \%$ uncertainty in particle number concentrations in each bin.

COD analysis has been used previously to assess spatial variability, and thorough reviews of these studies are available elsewhere (Wilson et al., 2005; Turner, 2008). Similar to previous reports, COD values greater than approximately 0.20 are indicative of a relatively heterogeneous spatial distribution (Wilson et al., 2005).

\section{Results/discussion}

\subsection{Meteorology}

Meteorological data are shown in Tables 1 and 2. Average temperatures and relative humidity did not differ appreciably from site to site, although seasonal variation was observed. Data from site W2 indicate a drop in temperatures from July to December, but stable relative humidity levels throughout the sampling period. For most of the sites, northerly and westerly winds dominated in the sampling area. Diurnal wind profiles from selected sites indicate differences in wind patterns at various sampling sites. For example, wind directions from the west to southwest, consistent with sea breeze and converging air flows around the Palos Verdes peninsula are found at the SP1 site during the night and morning hours in the summer. West to northerly winds influence the LB1 site during the evenings and nights, but southerly winds occur during the midday. The diurnal wind patterns indicate that, although winds originate mostly from the north to west, southerlies can occur. Differences in wind patterns during this study provide clues regarding the sources influencing each site's particle number size distribution. A more complete discussion of the overall wind patterns at each study site is provided in Moore et al. (2009).

\subsection{Particle number size distributions}

SMPS data from each site resulted in 111 size intervals (95 size intervals in the COD and correlation analyses), which allow the determination of the relationship between sites as a function of particle size. Number size distributions varied widely from site to site, and were influenced by changing meteorological conditions and PM sources. Modes were present at a number of different particle sizes and they changed rapidly between measurements. Figure $2 \mathrm{a}-\mathrm{g}$ shows average particle number size distributions for each site and sampling period. The standard error of the mean for each sampling period, not shown for clarity, at most of the sites was on the order of $20-30 \%, 20 \%, 10 \%$, and $<5 \%$ for particle sizes $<30 \mathrm{~nm}, 30-100 \mathrm{~nm}$, and $100-150 \mathrm{~nm}$, and $150-730 \mathrm{~nm}$, respectively. Due to instrument limit of detection, particles less than $14 \mathrm{~nm}$ were not accounted for; therefore, the results presented here do not include a possible nucleation mode (Ronkko et al., 2006). 

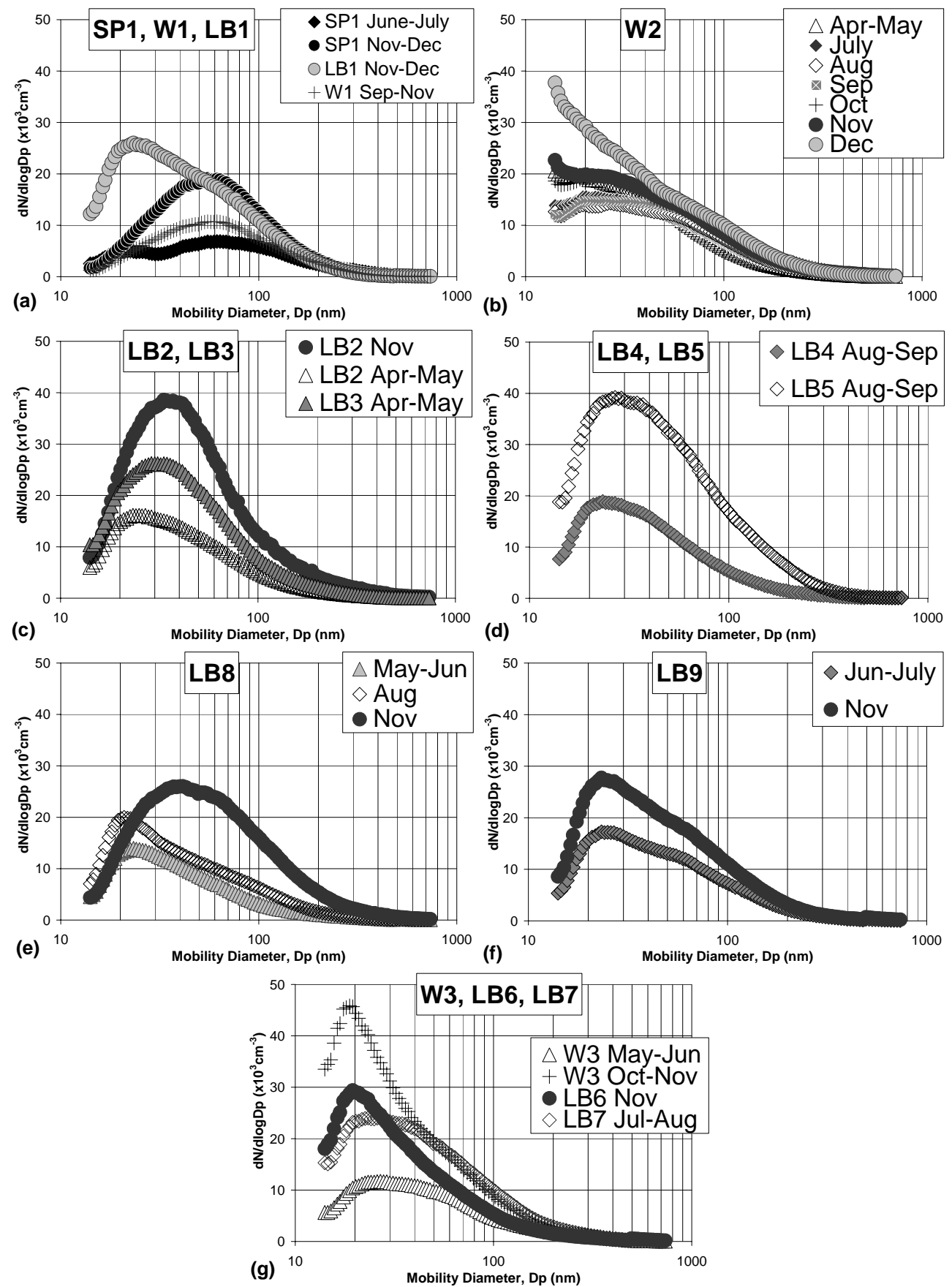

Fig. 2. Average number-based particle size distributions measured during each sampling period at each site.

For most of the sites, a single mode is present at particle sizes 20-60 nm, although modes and shapes of number size distributions vary depending on the site, time of day, and season. Other studies conducted in close proximity to vehicular exhaust have observed unimodal size distributions due to the high nucleation mode concentrations. A number of previous studies have also characterized urban aerosols by single modes (Ronkko et al., 2006, 2007; Morawska et al., 2007).
Although sources other than vehicular emissions impact the study sites (refineries, power plants, port operations, and marine vessels), their influence on the size distribution measured in this study is most likely overshadowed by the proximity of sites to heavily trafficked roadways and the overwhelming volume of vehicular emissions. Industrial facilities, such as power plants and waste incineration plants have been shown to exhibit bimodal size distributions with nuclei modes located between $20-30 \mathrm{~nm}$ and $30-40 \mathrm{~nm}$, 
and accumulation modes between $50-55 \mathrm{~nm}$ and $80-140 \mathrm{~nm}$ (Morawska et al., 2006; Maguhn et al., 2003). These studies acknowledged that while the location of the modes was stable, the concentration of particles within these modes was variable, making one or the other mode less visible in the distribution. The absence of this bimodality in our data set, therefore, can be attributed to either absence or insignificant impact of industrial sources, or the limitation of using particle number size distributions to discern industrial emissions from vehicular emissions.

\subsubsection{Seasonal variability}

Where data were available, seasonal variations were observed between the summer and fall/winter months. Number size distributions from the November and December periods show overall higher concentrations. Seasonal differences are observed at LB2, LB8, LB9, and W3 (Fig. 2c, e, f). Previous investigations of particle number size distributions in the Long Beach area show that average particle number concentrations are higher in winter than in the summer and that larger number median diameters in winter compared to summer may be due to higher relative humidity contributing to growth of particles by condensation of water vapor (Singh et al., 2006). The decreased mixing height observed in the Los Angeles region during the winter season can influence particle number concentrations. Total particle number concentrations calculated by summing across all size intervals measured by the SMPS (Table 1) and simultaneous measurements of total particle number concentrations (Moore et al., 2009) show distinct seasonal patterns, with relatively higher levels observed in the fall/winter than in the summer. During the fall, Santa Ana wind conditions with strong, dry offshore wind flows, mostly in late October did not result in appreciably different particle number size distributions.

Background sites, SP1, W1, and LB1 are grouped together in Fig. 2a. Lowest concentrations are observed at SP1 during the summer, with similar concentrations for particles $<20 \mathrm{~nm}$ in November and December. The increase in number concentrations for particles $20-120 \mathrm{~nm}$ can be attributed to the shifts in wind patterns during late November and early December. Mostly calm and northerly winds were observed during the night and morning hours, bringing particles from the heavilytrafficked Wilmington area, the Port of Los Angeles, and local traffic in San Pedro as well as Port trucking on arterial streets. A similar number size distribution is observed at the W1 site during the fall season, with a predominant mode at around $50-70 \mathrm{~nm}$ and average geometric number mean particle size of $60 \mathrm{~nm}$ (Table 1). The broader mode with larger particle sizes at the background locations compared to the inland sites, LB2-LB9, where modes occur at 20-30 nm and average geometric mean diameters are between $33-46 \mathrm{~nm}$, is consistent with previous studies comparing urban areas to coastal and background locations (Turner, 2008; Weijers et al., 2004).
W2 was sampled continuously from April to December and shows seasonal differences in particle number concentrations (Fig. 2b). Lowest concentrations for particles $<20 \mathrm{~nm}$ are observed in September, followed by August, July, October, April-May, November, and December. The peaks in the data are not necessarily consistent with peaks in port container traffic and associated peaks in truck traffic, which occur in August and September in advance of the holiday season (Port of Long Beach, 2007; Port of Los Angeles, 2007), suggesting that the increase in diesel traffic emissions does not alone increase UFP concentrations. Local traffic can influence particle number distributions as well. In contrast to the seasonal patterns discussed above for the other sites, W2 shows that, although winter concentrations are relatively higher, spring and summer levels can also be high, especially for the smallest particles. Total particle number concentrations in Table 1 show highest levels in December, with lowest concentrations in the spring/summer, consistent with expected seasonal patterns.

Quantitative analysis on the meteorological parameters was outside of the scope of this study; therefore, only general trends in wind speeds and direction were used to explain seasonal differences observed in the data. No distinguishable differences in meteorological parameters can be identified to explain the seasonal differences, but shifts in winds and local traffic patterns on a diurnal basis may be responsible for the high particle levels during the spring and summer months. Previous investigations of seasonal patterns in the Long Beach area near the I-710 indicate that lower ambient temperatures favor greater particle number concentrations in the $6-25 \mathrm{~nm}$ size range and a smaller number concentration in the 50-200 $\mathrm{nm}$ particle size range (Zhu et al., 2004). These trends can be seen at LB3, LB8, and at W2.

\subsubsection{Diurnal variability}

The diurnal and season patterns in particle number size distributions are shown in Fig. 3a-d. Corresponding wind directions at site W2 during the nighttime (20:00-06:00), morning commute (07:00-10:00), midday (11:00-14:00), and evening commute (15:00-19:00) are presented in Table 2. For most months, evening and nighttime particle number concentrations are lower than morning and daytime levels. Relatively higher particle number concentrations, especially for particles $<50 \mathrm{~nm}$, occur during the morning commute hours and stay elevated throughout the day, dropping in the evening. Particles in the $50-100 \mathrm{~nm}$ size range, associated with diesel fuel combustion (Mejia, 2008), also show higher concentrations during the morning commute hours, with lowest levels in the afternoon. A limited study of traffic counts conducted at the intersection of Harry Bridges and the I-110 in 2006 reveal a diurnal pattern in total vehicle counts, especially port-related heavy-duty diesel trucks (Houston, 2008), which may explain the diurnal patterns observed in particle number concentrations. Volumes of diesel trucks increase 

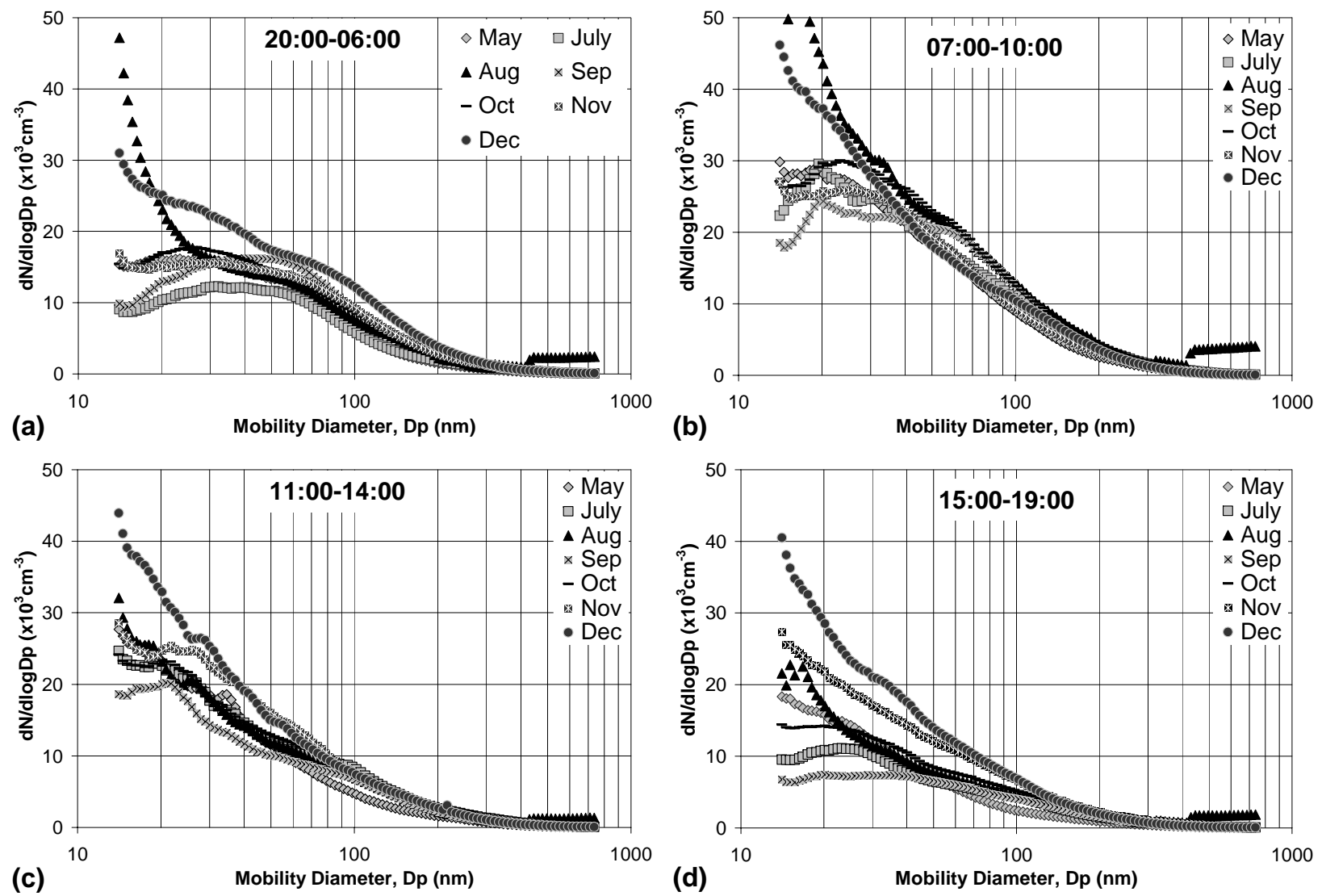

Fig. 3. Diurnal and seasonal patterns in number size distributions at site W2 during: (a) nighttime (20:00-06:00), (b) morning commute (07:00-10:00), (c) midday (11:00-14:00), and (d) evening commute (15:00-19:00). All times are Pacific Standard Time (PST).

during the morning commute hours, reaching approximately 400 trucks per hour by 09:00-10:00, and remain at around 300 trucks per hour throughout the day, increasing to 500 trucks during the 14:00-15:00 $\mathrm{h}$. The wind shift from north to northwest as the day progresses from morning to evening further indicates that the diurnal pattern observed at W2 is driven by changes in UFP sources influencing the site.

Analysis of the diurnal patterns in number size concentrations at site W2 between weekdays (Monday-Friday) and weekends (Saturday and Sunday) are shown in Fig. S1 in the supplemental materials (http://www.atmos-chem-phys. net/9/1061/2009/acp-9-1061-2009-supplement.pdf). We did not find differences in the location of modes between weekdays and weekends, only differences in absolute particle number concentrations, where weekday particle numbers were higher than on the weekends for all time periods. Similar results have been found in other studies (Hussein et al., 2005). The biggest difference in particle number is expected due to the large volume of local passenger and truck traffic in the area.

Diurnal profiles for sites close to major emission sources, such as LB4 and LB5 show that minimum number concentrations occur during the nighttime hours, but maximum lev- els are highly dependent on the location of the sampling site (Figs. 4a-b). During the morning commute hours, a bi-modal distribution is observed at LB5, with a peak at $20-30 \mathrm{~nm}$ and a smaller one at $60-70 \mathrm{~nm}$. Particle number size distributions from vehicular emissions have previously been shown to have a nucleation mode at around $20 \mathrm{~nm}$ arising from the condensation of organic species onto solid nuclei (Morawska and Zhang, 2002), or by binary homogeneous nucleation after the exhaust tube (Ronkko et al., 2006). A second submode has been found at around $60 \mathrm{~nm}$ arising from primary exhaust particles originating from fuel combustion or transformational growth of smaller particles by coagulation and vapor condensation (Geller et al., 2005; Jamriska et al., 2004). Number concentrations for particles in the size range of 40$60 \mathrm{~nm}$, associated with diesel engine emissions (Ntziachristos et al., 2007; Robert et al., 2007), remain relatively high throughout the day, decreasing into the evening and night.

\subsubsection{Spatial variability}

Our spatial variability analysis identified clear differences between concurrently sampled sites. COD values calculated for each site pair monitored simultaneously and then averaged across all pairs and sampling periods, show an 

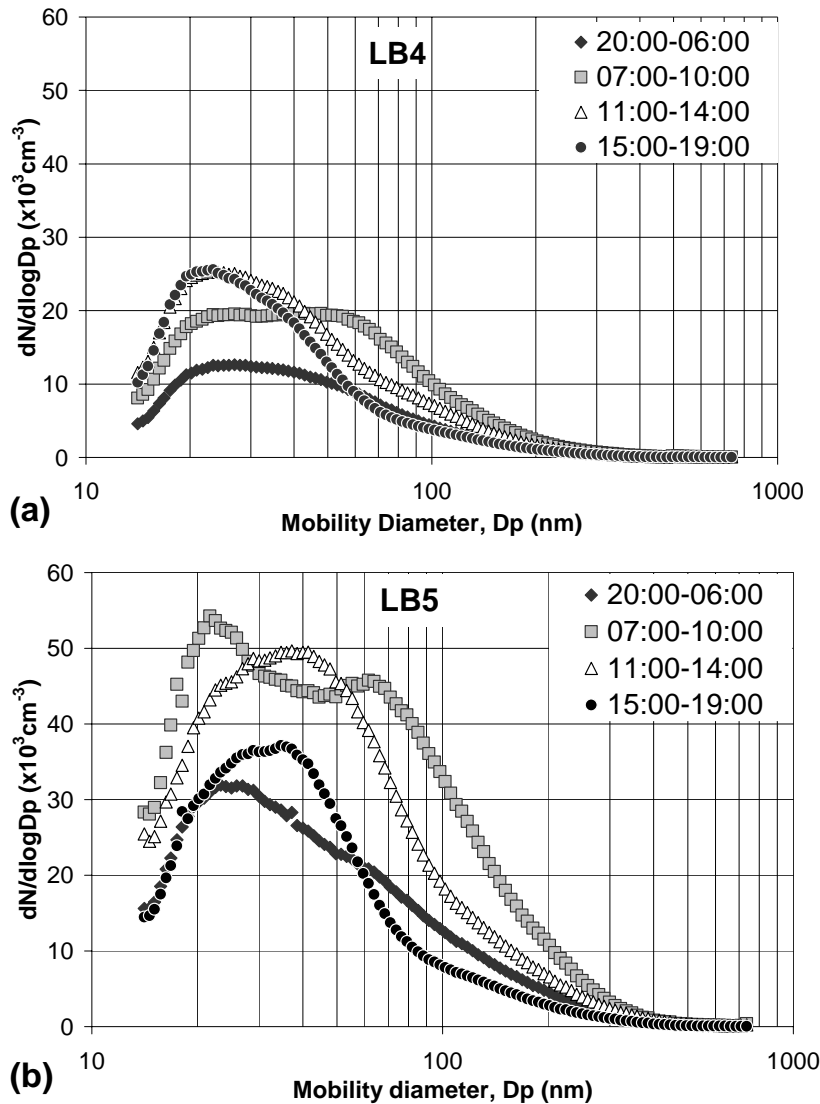

Fig. 4. Diurnal patterns in number size distributions at sites: (a) LB4 and (b) LB5.

inverse relationship between particle size and CODs (Fig. 5). Overall, number concentrations of particles less than $30 \mathrm{~nm}$ differ from site to site, whereas particles greater than $30 \mathrm{~nm}$ tend to have more similar concentrations at various sampling locations. Based on the previously discussed definition of spatial variability, results from this study show that, on average, COD values are greater than 0.2 for all particle sizes measured, suggesting moderate to high spatial heterogeneity. In addition to COD analysis, Spearman correlation coefficients $(r)$ were used to measure the strength of association between two sampling sites, where high $\mathrm{r}$ values indicate that the contribution of particles were similar for both sites throughout the sampling period.

Comparison of background locations, SP1 and LB1 illustrated in Fig. 6a shows that even sites considered clean and relatively far away from most combustion sources show vast spatial differences. Very high spatial divergence is observed for particles $<20 \mathrm{~nm}$, with decreasing spatial heterogeneity for particles in the $20-40 \mathrm{~nm}$ size range. This difference is driven by much higher concentration in particles $<30 \mathrm{~nm}$ at LB1 (Fig. 2a). Although both sites are located at the edge of the ocean, LB1 is close to the Port of Long Beach and is influenced by transient emissions from ships entering and

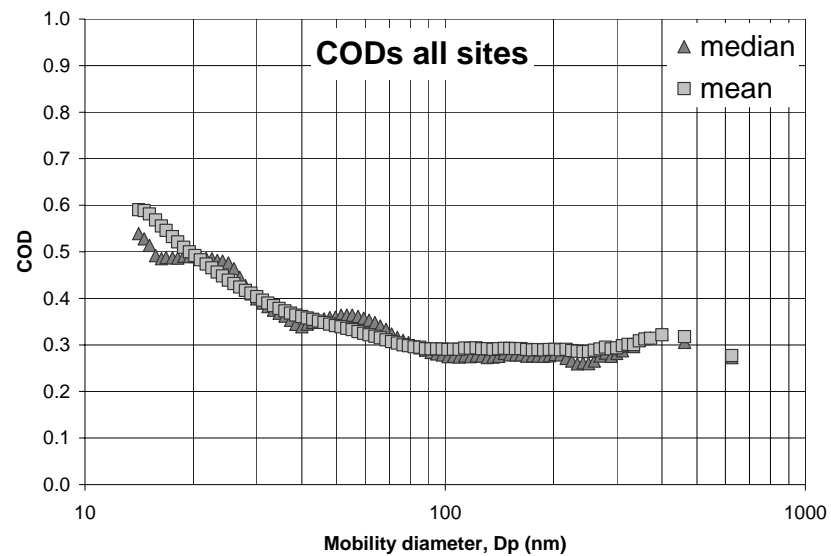

Fig. 5. Median and mean CODs across all sites and sampling periods.

leaving the harbor, other diesel vehicle emissions servicing the incoming cargo, as well as auxiliary engines. Diurnal wind patterns (Table 2) show that differences in wind directions during the afternoon and evening hours can also contribute to these high UFP levels. The wind shift during the late fall period (November-December) created particle number size distributions influenced by emissions from the Port at LB1. Appreciably higher overall particle number concentrations were measured at LB1 compared to SP1 (Table 1 and Moore et al., 2009). Strong correlations $(r=0.7-0.8)$ indicate that although differences in absolute concentrations between the sites can be great for UFPs and smaller for accumulation range PM, sources influencing the differently sized PM are constant throughout the 10-day sampling period.

Particle number size distributions from ship emissions have shown pronounced nucleation modes $(10-100 \mathrm{~nm})$ and size distributions characteristic of vehicular emissions ( $\mathrm{Hy}-$ varinen et al., 2008), although peaks in nucleation modes were dependent on engine type (Hobbs et al., 2000). Quickly vanishing Aitken mode $(\sim 20 \mathrm{~nm})$ has been found for ship plumes emitted in Asia (Lin et al., 2007). Bi-modal distributions have been observed, although the mode locations are ship-dependent. For example, some ship emissions have been characterized by a strong mode centered at $15 \mathrm{~nm}$ and a second but slightly weaker mode centered around $50 \mathrm{~nm}$ (Petzold et al., 2008), while others show a dominant mode $<40 \mathrm{~nm}$ and another, much weaker mode in the range 70 $100 \mathrm{~nm}$ (Isakson et al., 2001). Mono-modal distributions with mean particle diameters of $25-40 \mathrm{~nm}$ and no accumulation modes have also been observed (Kasper et al., 2007). Although the average size distribution observed at SP1 during late fall/winter shows a single mode at $\sim 25 \mathrm{~nm}$, due to the mixture of sources impacting that site, it is not possible to attribute the observed size distribution to ship emissions only. 

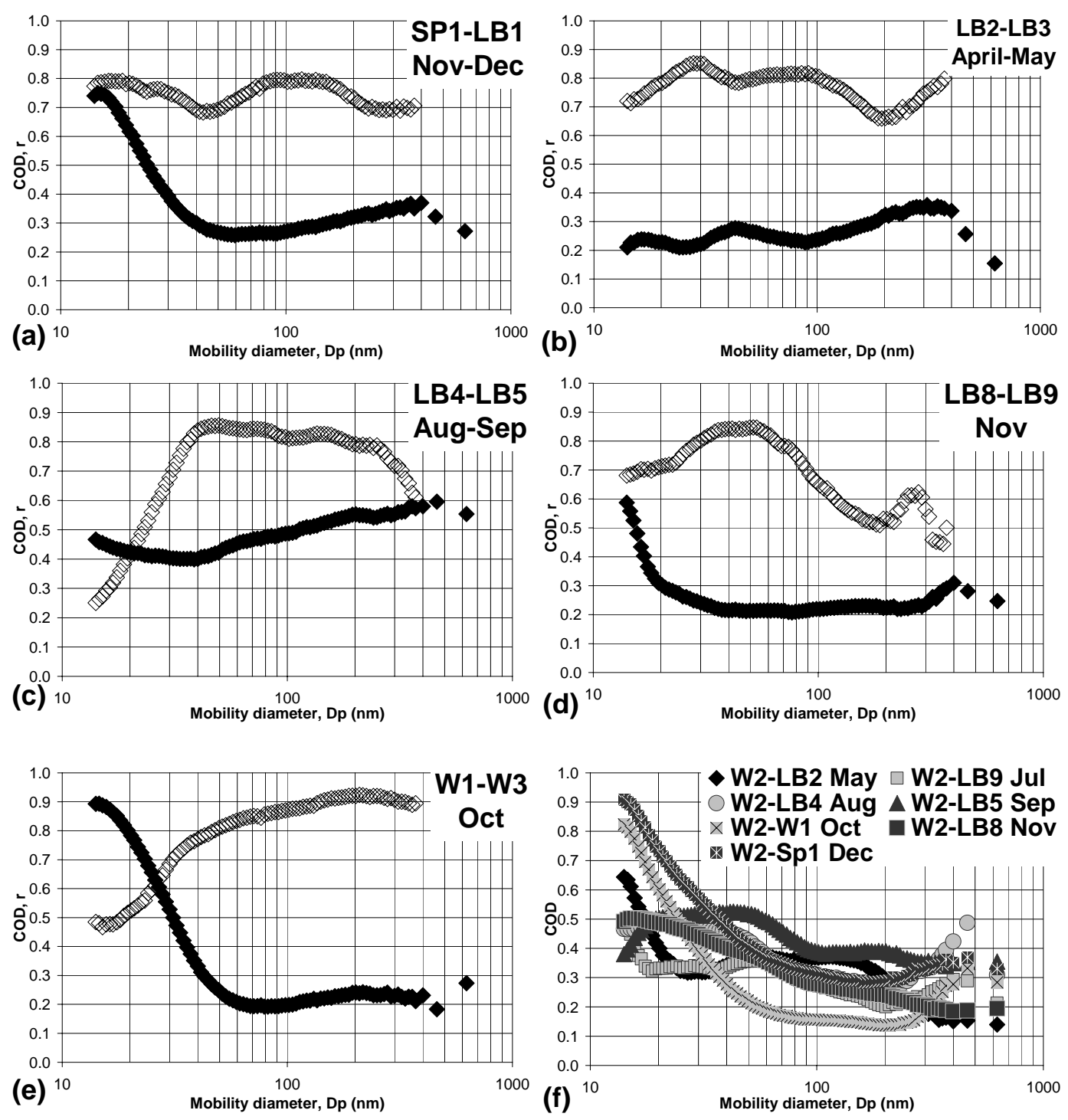

Fig. 6. CODs and correlations coefficients for selected site pairs. (a) SP1-LB1 in November-December, (b) LB2-LB3 in April-May, (c) LB4-LB5 in August-September, (d) LB8-LB9 in November, (e) W1-W3 in October, and (f) LB2 with selected sites (assorted months). Closed and open symbols indicated COD and $r$ values, respectively.

Relatively low spatial divergence $(\mathrm{COD}=0.15-0.35)$ and high correlation coefficients $(r=0.65-0.85)$ observed in Fig. $6 \mathrm{~b}$ are expected for sites separated by only about $320 \mathrm{~m}$ and impacted by similar PM sources. A truck parking lot is adjacent to the LB3 site, and the LB2 site is no more than $15 \mathrm{~m}$ away from a major diesel truck route. Both sites exhibit similar particle number size distributions with average geometric number mean particle size of about $42 \mathrm{~nm}$ (Table 1) and modes at $20-30 \mathrm{~nm}$ and $30-40 \mathrm{~nm}$ at LB3 and LB2, respectively (Fig. 2c), characteristic of diesel exhaust emissions (Ntziachristos et al., 2007; Ogulei et al., 2007). Although both gasoline and diesel vehicles can emit particles in the $20-40 \mathrm{~nm}$ size range, particle number concentrations emitted from diesel vehicles dominate those emitted by gasoline-powered cars (Geller et al., 2005). Higher absolute concentrations at LB3 are attributed to the idling heavy-duty diesel trucks.

Results from concurrently sampled LB4 and LB5 show that sites separated by about $600 \mathrm{~m}$ can experience differences in particle number size distributions. Although the shapes of the size distributions are similar (Fig. 2d), with geometric mean diameters at $40-45 \mathrm{~nm}$, LB5 is clearly influenced by more particles in all size ranges than LB4, which is further east of the freeway. Very high traffic emissions increase particle number concentrations in the $20-40 \mathrm{~nm}$ size range by two-fold at LB5 compared to LB4, consistent with previous observations on the I-710 (Westerdahl et al., 2005; Zhu et al., 2002b). CODs in Fig. 6c show a uniformly high spatial divergence $(C O D>0.40)$ between the two sites across all particle sizes. Correlation coefficients are uniform 
at around 0.80 for particles $40-200 \mathrm{~nm}$, but a much weaker relationship between the sites exists for $14-30 \mathrm{~nm}$ particles $(r=0.25-0.70)$ and slightly weaker for $300-400 \mathrm{~nm}$ particles $(r=0.60-0.70)$. These results imply that although the two sites differ in their particle number concentrations, especially for accumulation mode particles, the differences are constant throughout the 2-week sampling period. Particles $<40 \mathrm{~nm}$ are much higher in their number concentrations at LB5, but the local emission sources driving these differences affect the two sites at different times. Because LB5 is directly next to the freeway, it is constantly impacted by vehicular emissions and the turbulence induced by the freeway traffic has a large impact on the particle number concentrations. Changes in meteorological conditions will not affect particle number concentrations at LB5 to the same extend as LB4, which is not located directly next to significant UFP emission sources. As noted in earlier studies, vehicular sources vary widely in their emission characteristics and affect number size distributions to a great extent, especially further away from roadways (Harrison et al., 1999; Zhu et al., 2002b).

LB8 and LB9 are $350 \mathrm{~m}$ apart and both are close to numerous particle sources, including a freeway, rail, local roadways, and the ICTF serviced by diesel trucks. LB8, located about $100 \mathrm{~m}$ east of the SR-103 carrying up to 2000 vehicles per hour including 700 diesel vehicles, 600 of which are heavy-duty port-related trucks (Houston, 2008), has a broad mode at $20-50 \mathrm{~nm}$ in its size distribution (Fig. 2e). The ICTF frequently experiences substantial queuing as trucks wait to exit the freeway, thus emissions from idling and accelerating trucks impact LB8, especially during daytime hours. A distinct mode at $25 \mathrm{~nm}$ and a smaller mode at $60-70 \mathrm{~nm}$ occur at LB9 (Fig. 2f), which experiences emissions from the adjacent ICTF (the congested Willow street, which serves as the northern terminus of the Terminal Island Freeway), and rail, which passes $90 \mathrm{~m}$ east of the sampling site. The two larger modes observed are consistent with observations conducted $30 \mathrm{~m}$ and $90 \mathrm{~m}$ from the I-710 (Zhu et al., 2002b).

The spatial variability analysis shown in Fig. 6d illustrates heterogeneity for particles $<30 \mathrm{~nm}(\mathrm{COD}=0.25-0.6)$ and relatively low divergence for the larger particles $(\mathrm{COD}=0.2)$, consistent with the differences in the shapes of the size distributions. Comparison of these two sites illustrates that differences in absolute particle number concentrations between two sites do not have to be large to create spatial heterogeneity for particles in certain size ranges. Again, it is important to note that the variation in correlation coefficients as a function of particle size is not consistent with the variation in the CODs. Relatively moderate association exists for particles $<20 \mathrm{~nm}(r \approx 0.70)$, corresponding to high COD values of $\approx 0.3-0.6$. High correlations for particles in the $30-70 \mathrm{~nm}$ size range $(r \approx 0.85)$, lower correlations for $200 \mathrm{~nm}$ particles $(r \approx 0.50)$, and a moderate association for $300 \mathrm{~nm}$ particles $(r \approx 0.6)$ are all associated with persistently low COD values of about 0.20 . Variability in the temporal association between the sites may arise from transient events, such as
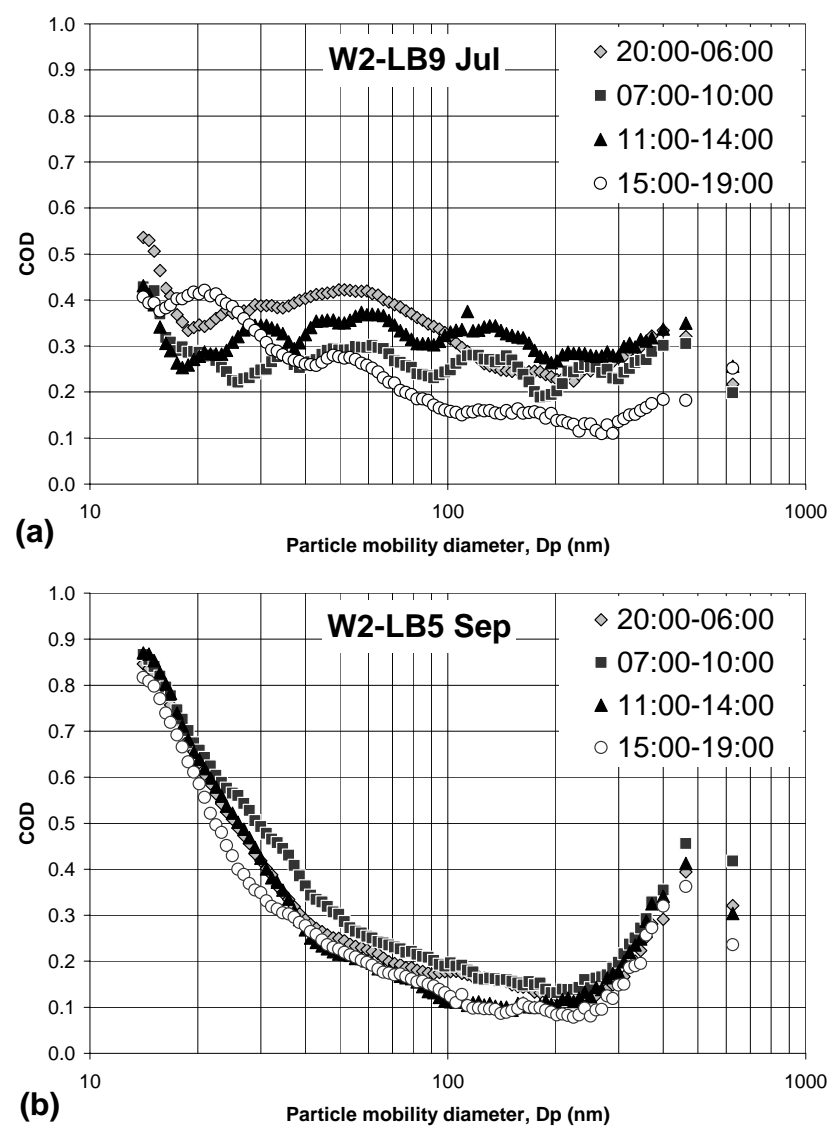

Fig. 7. Diurnal patterns in CODs for selected site pairs (a) LB2 and LB9 in July, and (b) LB2 and LB5 in September.

railroad emissions at LB9 and diesel exhaust emissions from trucks idling and accelerating.

Spatial and diurnal variability result from differences in traffic patterns, especially diesel vehicles transporting goods from the ports. The extended hours of operations of the ports and truck-related facilities is driven by the success of the PierPass program, which provides incentives for cargo owners to move cargo at night and on weekends by charging a traffic mitigation fee on container movements during peak hours (PierPass, 2008). While the goal is to reduce truck traffic and pollution during peak daytime hours and to alleviate port congestion, the program could extend the hours nearby community residents are exposed to port truck traffic and UFP emissions.

Comparison of W1 and W3 sites shows an expected inverse relationship between CODs and correlation coefficients for sites that differ in their ultrafine particle number size distributions (Fig. 6e). Very high COD values of 0.90 are observed for $15 \mathrm{~nm}$ particles, decreasing to levels considered spatially homogeneous for particles $>60 \mathrm{~nm}$. In comparison to $\mathrm{W} 3$, W1 experiences minimal impact from vehicular emissions, and PM levels measured at that site can often be attributed to emissions from nearby port activities. The broad 
mode observed in Fig. 2a and the average geometric number mean particle size of $60 \mathrm{~nm}$ are similar to observations conducted at nighttime in an urban environment, where a mode of $50-70 \mathrm{~nm}$ was associated with lack of significant emissions and particle growth due to coagulation and condensation of semi-volatile species onto pre-existing particles (Rodriguez et al., 2007). Although concentrations of particles $<50 \mathrm{~nm}$ are very different between the two sites, the correlation coefficients for particles $>100 \mathrm{~nm}$ show excellent temporal association $(r \approx 0.90)$ between the sites. Similar sources of accumulation mode PM affect the two sites.

The variation in spatial divergence as a function of particle size is illustrated in Fig. 6f. W2 is compared to 8 other locations, resulting in a range of site-specific COD values. Very high spatial heterogeneity (COD $>0.80$ ) occurs in comparison to the background SP1 and W1 sites, especially for freshly emitted particles $<20 \mathrm{~nm}$ due to the difference in observed absolute concentrations according to a definition of COD (Turner, 2008). Lowest spatial divergence for particles $<20 \mathrm{~nm}$ is observed by comparing W2 to LB5 and LB9, all of which are located very close to roadways with high traffic volumes, similar to the W2 site. Low spatial divergence $(C O D \approx 0.15)$ occurs for particles in the $80-300 \mathrm{~nm}$ size range between sites $\mathrm{W} 2$ and $\mathrm{W} 1$, implying that both sites are influenced by similar sources that emit particles in all size ranges.

Spatial variability on a diurnal scale was investigated by comparing W2 to LB9 and LB5 during 4 time periods (Fig. 7a-b). COD values for the W2-LB9 site pair shows clear diurnal differences, driven by the midday and evening commute hours. An interesting pattern in COD values as a function of particle size is revealed for the 11:00-14:00 period, when the CODs are temporally resolved. Spatial divergence is moderately high and uniform $(C O D \approx 0.30)$ for all particle size ranges, although some fluctuations exist. As discussed earlier, LB9 is located close to the rail and the ICTF, which may result in varying intensities of PM emissions during different times of the day. Differences in particle number concentrations are very similar regardless of the time of day when comparing W2 to LB5 (Fig. 7b). This similarity is presumably driven by the continuous PM emissions from the I-710 impacting LB5, and from the Harry Bridges Avenue close to W2. These results show that spatial variability is highly dependent on the PM sources impacting the sites and further, spatial variability can differ on a diurnal scale.

\section{Conclusions}

The study reported here investigated how particulate matter number concentrations from thirteen sites vary as a function of size, season, time of day, and location. PM number based size distributions in an urban environment are highly variable on temporal and spatial scales because of variations in mobile source patterns and local meteorological conditions.
Comparison of the number size distributions measured during different seasons showed that higher concentrations of particles $>20 \mathrm{~nm}$ and overall higher total PN concentrations are observed more often during the winter season than during the spring/summer season. Diurnal profiles for sites close to major emissions sources, such as LB4 and LB5 show that minimum number concentrations occur during the nighttime hours, but maximum levels are highly dependent on the location of the sampling sites and are most likely associated with variations in local traffic patterns, as observed in other studies (Lianou et al., 2007).

The spatial variability analysis showed concentrations of smaller particles are different at each sampling site, but larger particles tend to be more uniform, in general, which may be a signal of regional aerosol. Exceptions occur on a caseby-case basis. Both COD values and correlation coefficients were investigated to determine spatial variability. Correlation analysis provides information on the overall trend in association between two sites throughout the sampling period, while COD analysis shows differences in absolute concentrations among concurrently sampled sites. The two kinds of statistical analysis, therefore, provide a more complete assessment of spatial and temporal variability. COD values ranged from 0.10 to 0.90 (LB2-LB5 and W2-SP1, respectively), with usually high to moderate spatial variability for particles $<30 \mathrm{~nm}$, and moderate to low divergence for larger particles. Spatial heterogeneity exists between background and source sites especially for particles $<40 \mathrm{~nm}$ (SP1 and W2), and spatial homogeneity can be seen between geographically close sites (LB2 and LB3). Comparison of background locations showed that even sites considered clean and relatively far away from most combustion sources can exhibit vast spatial differences, especially for particles $<20 \mathrm{~nm}$. These differences can be seasonal and are influenced by changes in wind patterns, which in turn dictate the types of source emissions affecting particle number size distributions. These emissions include not only ships but also other diesel vehicles servicing the incoming cargo as well as auxiliary engines.

COD and correlation analyses reveal that the correlation coefficients as a function of particle size do not necessarily follow an expected inverse relationship with the COD values. While relatively moderate association may exists for some particle sizes, corresponding to high COD values, high correlation coefficients for other particle sizes can be associated with low COD values. Variability in the temporal association between the sites may arise from transient events, such as rail emissions and vehicular exhaust emissions from diesel trucks idling and accelerating. The large variation in spatial distributions as a function of particle size suggests that it is not possible to characterize a community-average concentration of particle number size distributions with only one monitoring station. To accurately determine human exposure to differently sized PM, spatial and temporal variability of PM needs to be assessed. Results presented here show that particle size distributions vary significantly on a community scale, 
and can differ depending on the season and time of day. Epidemiological studies assessing health effects related to PM exposure should not rely on only one monitoring site, but ought to use data collected from a large number of monitors located close to important UFP sources and operating during different seasons.

The large dataset obtained from this study will be used in future analysis to determine size distribution profiles of specific sources (ships, rail, diesel vehicles, port activities) using both detailed weather analysis (direction and speed), and detailed analysis of video data collected simultaneously with the SMPS observations at each site.

Acknowledgements. We would like to thank Payam Pakbin and Neelakshi Hudda for assistance in the field and Brigid Brett-Esborn for statistical consulting. The authors also acknowledge Pastor G. Johnson (Westside Baptist Church, Long Beach), D. Berns and D. Seymour (The Berns Company, Long Beach), D. Modha (the Long Beach Job Corps facility), C. Janocha (Superior Electrical Advertising, Long Beach), the Port of Los Angeles, the Port of Long Beach, G. Bertolin (SAIC), B. Alvarez, S. Wilson and P. Fine (SCAQMD), R. Veyna and T. Diaz (Orange County Nursery), Southern California Edison, J. Cross, J. Marquez, Battalion 6 (Los Angeles Fire Department), and A. Hricko of USC. This study was conducted as part of the multi-investigator Harbor Communities Monitoring Study (HCMS) funded by the Air Resources Board grant \#05-317. Research described in this paper was supported by the Center for Occupational and Environmental Health, the National Institute of Environmental Health Sciences, the Southern California Particle Center (SCPC), funded by EPA under the STAR program through Grant RD-8324-1301-0, the Southern California Environmental Health Sciences Center (SCEHSC) grant number 5P30 ES07048, and in part by the United States Environmental Protection Agency (EPA) under the Science to Achieve Results (STAR) fellowship program grant \#R832157. EPA has not officially endorsed this publication and the views expressed herein may not reflect the views of the EPA.

Edited by: K. Hämeri

\section{References}

Geller, M. D., Sardar, S. B., Phuleria, H., Fine, P. N., and Sioutas, C.: Measurements of particle number and mass concentrations and size distributions in a tunnel environment, Environ. Sci. Technol., 39, 8653-8663, 2005.

Harris, S. J. and Maricq, M. M.: Signature size distributions for diesel and gasoline engine exhaust particulate matter, J. Aerosol Sci., 32, 749-764, 2001.

Harrison, R. M., Jones, M., and Collins, G.: Measurements of the physical properties of particles in the urban atmosphere, Atmos. Environ., 33, 309-321, 1999.

Hobbs, P. V., Garrett, T. J., Ferek, R. J., Strader, S. R., Hegg, D. A., Frick, G. M., Hoppel, W. A., Gasparovic, R. F., Russell, L. M., Johnson, D. W., O'Dowd, C., Durkee, P. A., Nielsen, K. E., and Innis, G.: Emissions from ships with respect to their effects on clouds, J. Atmos. Sci., 57, 2570-2590, 2000.
Houston, D., Krudysz, M., and Winer, A.: Diesel truck traffic in port-adjacent low-income and minority communities: Environmental justice implications of near-roadway land use conflicts, Journal of the Transportation Research Board, 2076, 3846, 2008.

Hussein, T., Puustinen, A., Aalto, P. P., Mäkelä, J. M., Hämeri, K., and Kulmala, M.: Urban aerosol number size distributions, Atmos. Chem. Phys., 4, 391-411, 2004, http://www.atmos-chem-phys.net/4/391/2004/.

Hussein, T., Hameri, K. A., Aalto, P. P., Paatero, P., and Kulmala, M.: Modal structure and spatial-temporal variations of urban and suburban aerosols in helsinki - finland, Atmos. Environ., 39, 1655-1668, 2005.

Hyvarinen, A. P., Komppula, M., Engler, C., Kivekas, N., Kerminen, V. M., Dal Maso, M., Viisanen, Y., and Lihavainen, H.: Atmospheric new particle formation at uto, baltic sea 2003-2005, Tellus B, 60, 345-352, 2008.

Isakson, J., Persson, T. A., and Lindgren, E. S.: Identification and assessment of ship emissions and their effects in the harbour of g(o)over-circleteborg, sweden, Atmos Environ, 35, 3659-3666, 2001.

Jamriska, M., Morawska, L., Thomas, S., and He, C.: Diesel bus emissions measured in a tunnel study, Environ. Sci. Technol., 38, 6701-6709, 2004.

Jeong, C. H., Hopke, P. K., Chalupa, D., and Utell, M.: Characteristics of nucleation and growth events of ultrafine particles measured in rochester, ny, Environ. Sci. Technol., 38, 1933-1940, 2004.

Junker, M., Kasper, M., Roosli, M., Camenzind, M., Kunzli, N., Monn, C., Theis, G., and Braun-Fahrlander, C.: Airborne particle number profiles, particle mass distributions and particle-bound PAH concentrations within the city environment of Basel: An assessment as part of the Briska project, Atmos. Environ., 34, 3171-3181, 2000.

Kasper, A., Aufdenblatten, S., Forss, A., Mohr, M., and Burtscher, H.: Particulate emissions from a low-speed marine diesel engine, Aerosol. Sci. Technol., 41, 24-32, 2007.

Kerminen, V. M., Pakkanen, T. A., Makela, T., Hillamo, R. E., Sillanpaa, M., Ronkko, T., Virtanen, A., Keskinen, J., Pirjola, L., Hussein, T., and Hameri, K.: Development of particle number size distribution near a major road in helsinki during an episodic inversion situation, Atmos. Environ., 41, 1759-1767, 2007.

Ketzel, M., Wåhlin, P., Kristensson, A., Swietlicki, E., Berkowicz, R., Nielsen, O. J., and Palmgren, F.: Particle size distribution and particle mass measurements at urban, near-city and rural level in the Copenhagen area and Southern Sweden, Atmos. Chem. Phys., 4, 281-292, 2004, http://www.atmos-chem-phys.net/4/281/2004/.

Keywood, M. D., Ayers, G. P., Gras, J. L., Gillett, R. W., and Cohen, D. D.: Relationships between size segregated mass concentration data and ultrafine particle number concentrations in urban areas, Atmos. Environ., 33, 2907-2913, 1999.

Kim, C. S. and Jaques, P. A.: Respiratory dose of inhaled ultrafine particles in healthy adults, Philos. T. Roy. Soc. A, 358, 26932705, 2000.

Lehmann, U., Mohr, M., Schweizer, T., and Rutter, J.: Number size distribution of particulate emissions of heavy-duty engines in real world test cycles, Atmos. Environ., 37, 5247-5259, 2003.

Lianou, M., Chalbot, M. C., Kotronarou, A., Kavouras, I. G., 
Karakatsani, A., Katsouyanni, K., Puustinnen, A., Hameri, K., Vallius, M., Pekkanen, J., Meddings, C., Harrison, R. M., Thomas, S., Ayres, J. G., ten Brink, H., Kos, G., Meliefste, K., de Hartog, J. J., and Hoek, G.: Dependence of home outdoor particulate mass and number concentrations on residential and traffic features in urban areas, J. Air Waste Manage., 57, 1507-1517, 2007.

Lin, P., Hu, M., Wu, Z., Niu, Y., and Zhu, T.: Marine aerosol size distributions in the springtime over china adjacent seas, Atmos. Environ., 41, 6784-6796, 2007.

Maguhn, J., Karg, E., Kettrup, A., and Zimmermann, R.: On-line analysis of the size distribution of fine and ultrafine aerosol particles in flue and stack gas of a municipal waste incineration plant: Effects of dynamic process control measures and emission reduction devices, Environ. Sci. Technol., 37, 4761-4770, 2003.

Mejía, J. F., Morawska, L., and Mengersen, K.: Spatial variation in particle number size distributions in a large metropolitan area, Atmos. Chem. Phys., 8, 1127-1138, 2008,

http://www.atmos-chem-phys.net/8/1127/2008/.

Mercer Management Consulting: San Pedro Bay Ports Cargo Forecast Update, New York, 2001.

Monn, C.: Exposure assessment of air pollutants: A review on spatial heterogeneity and indoor/outdoor/personal exposure to suspended particulate matter, nitrogen dioxide and ozone, Atmos. Environ., 35, 1-32, 2001.

Moore, K., Krudysz, M. A., Pakbin, P., Hudda, N., and Sioutas, C.: Intra-community variability in total particle number concentrations in the San Pedro Harbor area (Los Angeles, California), Aerosol Sci. Technol., in press, 2009.

Morawska, L. and Zhang, J. J.: Combustion sources of particles. 1. Health relevance and source signatures, Chemosphere, 49, 10451058, 2002.

Morawska, L., Johnson, G. R., He, C., Ayoko, G. A., Lim, M. C. H., Swanson, C., Ristovski, Z. D., and Moore, M.: Particle number emissions and source signatures of an industrial facility, Environ. Sci. Technol., 40, 803-814, 2006.

Morawska, L., Ristovski, Z. D., Johnson, G. R., Jayaratne, E. R., and Mengersen, K.: Novel method for on-road emission factor measurements using a plume capture trailer, Environ. Sci. Technol., 41, 574-579, 2007.

Ntziachristos, L., Ning, Z., Geller, M. D., and Sioutas, C.: Particle concentration and characteristics near a major freeway with heavy-duty diesel traffic, Environ. Sci. Technol., 41, 2223-2230, 2007.

Ogulei, D., Hopke, P. K., Ferro, A. R., and Jaques, P. A.: Factor analysis of submicron particle size distributions near a major united states-canada trade bridge, J. Air Waste Manage., 57, 190-203, 2007.

Petzold, A., Hasselbach, J., Lauer, P., Baumann, R., Franke, K., Gurk, C., Schlager, H., and Weingartner, E.: Experimental studies on particle emissions from cruising ship, their characteristic properties, transformation and atmospheric lifetime in the marine boundary layer, Atmos. Chem. Phys., 8, 2387-2403, 2008, http://www.atmos-chem-phys.net/8/2387/2008/.

Pierpass program: http://www.pierpass.org/, access: 5 February 2009, 2008.

Port of Long Beach port statistics: Port of Long Beach, Long Beach, http://www.polb.com/about/port_stats/default.asp., access: 5 February 2009, 2007.
Port of Los Angeles port statistics facts \& figures: Port of Los Angeles, Los Angeles, CA, http://www.portoflosangeles.org/stats/ stats_2007.htm, access: 5 February 2009, 2007.

Puustinen, A., Hameri, K., Pekkanen, J., Kulmala, M., De Hartog, J., Meliefste, K., Ten Brink, H., Kos, G., Katsouyanni, K., Karakatsani, A., Kotronarou, A., Kavouras, I., Meddings, C., Thomas, S., Harrison, R., Ayres, J. G., Van der Zee, S., and Hoek, G.: Spatial variation of particle number and mass over four european cities, Atmos. Environ., 41, 6622-6636, 2007.

Ristovski, Z. D., Morawska, L., Bofinger, N. D., and Hitchins, J.: Submicrometer and supermicrometer particulate emission from spark ignition vehicles, Environ. Sci. Technol., 32, 3845-3852, 1998.

Robert, M. A., Kleeman, M. J., and Jakober, C. A.: Size and composition distributions of particulate matter emissions: Part 2 heavy-duty diesel vehicles, J. Air Waste Manage., 57, 14291438, 2007.

Rodríguez, S., Van Dingenen, R., Putaud, J.-P., Dell'Acqua, A., Pey, J., Querol, X., Alastuey, A., Chenery, S., Ho, K.-F., Harrison, R., Tardivo, R., Scarnato, B., and Gemelli, V.: A study on the relationship between mass concentrations, chemistry and number size distribution of urban fine aerosols in Milan, Barcelona and London, Atmos. Chem. Phys., 7, 2217-2232, 2007 , http://www.atmos-chem-phys.net/7/2217/2007/.

Ronkko, T., Virtanen, A., Vaaraslahti, K., Keskinen, J., Pirjola, L., and Lappi, M.: Effect of dilution conditions and driving parameters on nucleation mode particles in diesel exhaust: Laboratory and on-road study, Atmos. Environ., 40, 2893-2901, 2006.

Ronkko, T., Virtanen, A., Kannosto, J., Keskinen, J., Lappi, M., and Pirjola, L.: Nucleation mode particles with a nonvolatile core in the exhaust of a heavy duty diesel vehicle, Environ. Sci. Technol., 41, 6384-6389, 2007.

Rosenbohm, E., Vogt, R., Scheer, V., Nielsen, O. J., Dreiseidler, A., Baumbach, G., Imhof, D., Baltensperger, U., Fuchs, J., and Jaeschke, W.: Particulate size distributions and mass measured at a motorway during the bab ii campaign, Atmos. Environ., 39, 5696-5709, 2005.

Singh, M., Bowers, K., and Sioutas, C.: Seasonal and spatial trends in particle number concentrations and size distributions at the children's health study sites in southern california, J. Expo. Sci. Env. Epid., 16, 3-18, 2006.

Su, D. S., Muller, J. O., Jentoft, R. E., Rothe, D., Jacob, E., and Schlogl, R.: Fullerene-like soot from euroiv diesel engine: Consequences for catalytic automotive pollution control, Top. Catal., 30-31, 241-245, 2004.

Turner, J. R. and Allen, D. T. : Transport of atmospheric fine particulate matter: Part 2 - findings from recent field programs on the intraurban variability in fine particulate matte, J. Air Waste Manage., 58, 196-215, 2008.

Weijers, E. P., Khlystov, A. Y., Kos, G. P. A., and Erisman, J. W.: Variability of particulate matter concentrations along roads and motorways determined by a moving measurement unit, Atmos. Environ., 38, 2993-3002, 2004.

Westerdahl, D., Fruin, S., Sax, T., Fine, P. M., and Sioutas, C.: Mobile platform measurements of ultrafine particles and associated pollutant concentrations on freeways and residential streets in los angeles, Atmos. Environ., 39, 3597-3610, 2005.

Wilson, J. G., Kingham, S., Pearce, J., and Sturman, A. P.: A review 
of intraurban variations in particulate air pollution: Implications for epidemiological research, Atmos. Environ., 39, 6444-6462, 2005.

Yao, X. H., Lau, N. T., Fang, M., and Chan, C. K.: Correlations of ambient temperature and relative humidity with submicron particle number concentration size distributions in on-road vehicle plumes, Aerosol Sci. Technol., 41, 692-700, 2007.

Zhang, K. M. and Wexler, A. S.: Modeling the number distributions of urban and regional aerosols: Theoretical foundations, Atmos. Environ., 36, 1863-1874, 2002.

Zhang, K. M., Wexler, A. S., Zhu, Y. F., Hinds, W. C., and Sioutas, C.: Evolution of particle number distribution near roadways. Part ii: The 'road-to-ambient' process, Atmos. Environ., 38, 66556665,2004
Zhu, Y., Hinds, W. C., Kim, S., Sioutas, C.: Concentration and size distribution of ultrafine particles near a major highway, J. Air Waste Manage., 52, 1032-1042, 2002a.

Zhu, Y., Hinds, W. C., Kim, S., Shen, S., and Sioutas, C.: Study of ultrafine particles near a major highway with heavy-duty diesel traffic, Atmos. Environ., 36, 4323-4335, 2002b.

Zhu, Y. F., Hinds, W. C., Shen, S., and Sioutas, C.: Seasonal trends of concentration and size distribution of ultrafine particles near major highways in los angeles, Aerosol Sci. Technol., 38, 5-13, 2004. 